Portland State University

PDXScholar

Psychology Faculty Publications and

Presentations

Psychology

2017

\title{
What is the Key to Culturally Competent Care: Reducing Bias or Cultural Tailoring?
}

\author{
Adolfo Gabriel Cuevas \\ Portland State University \\ Kerth O'Brien \\ Portland State University \\ Somnath Saha \\ Portland Veterans Affairs Medical Center
}

Follow this and additional works at: https://pdxscholar.library.pdx.edu/psy_fac

Part of the Health Psychology Commons

Let us know how access to this document benefits you.

\section{Citation Details}

Cuevas, A. G., O'Brien, K., \& Saha, S. (2017). What is the key to culturally competent care: Reducing bias or cultural tailoring?. Psychology \& Health, 32(4), 493-507.

This Article is brought to you for free and open access. It has been accepted for inclusion in Psychology Faculty Publications and Presentations by an authorized administrator of PDXScholar. Please contact us if we can make this document more accessible: pdxscholar@pdx.edu. 


\title{
What is the key to culturally competent care: Reducing bias or cultural tailoring?
}

\author{
Adolfo G. Cuevas ${ }^{\mathrm{a}, \mathrm{c} *}$, Kerth O'Brien ${ }^{\mathrm{a}}$ and Somnath Saha ${ }^{\mathrm{b}}$ \\ ${ }^{a}$ Department of Psychology, Portland State University, Portland, OR, USA; ${ }^{b}$ Portland Veterans \\ Affairs Medical Center, Public Health \& Preventive Medicine, Medical Informatics \& Clinical \\ Epidemiology, Oregon Health \& Science University, Portland, OR, USA; ${ }^{\circ}$ Department of Social \\ and Behavioral Sciences, Harvard T.H. Chan School of Public Health, Boston, MA, USA
}

(Received 28 July 2016; accepted 15 January 2017)

\begin{abstract}
Objective: To gain a better understanding as to whether disparities in patientprovider relationships arise from ethnic minority patients being treated differently than European American patients while they would prefer to be treated the same, or whether disparities arise when ethnic minority patients are treated the same as European American patients while they would prefer to be treated differently.

Method: African-American, Latina/Latino and European American community members were recruited to participate in one of 27 focus group discussions. Topics included what made a good or bad relationship with a doctor and what led one to trust a doctor. A thematic analysis was conducted using NVivo 10.

Results: Patients of all groups described experiences that reflected the concepts of patient-centred care, such as wanting a clinician who is attentive to patients' needs. African-American patients reported experiences they viewed as discriminatory. Some African-American patients felt it was appropriate to racially/ethnically contextualise their care, and most Latina/Latino patients preferred language/culturally concordant clinicians.

Conclusion: Health care disparities might be reduced through a patientcentred approach to cultural competency training, general knowledge of the cultural context of clinicians' patient population, and attention to the effects of racial bias and discrimination among both clinicians and non-clinical staff.
\end{abstract}

Keywords: clinician-patient relationships; patient-centred care; cultural competency; health care disparities; ethnic minorities; focus groups

\section{Introduction}

Despite efforts through community interventions and health care training programmes, health care disparities persist for African-Americans and Latinas/Latinos (National Center for Health Statistics, 2016; Shi et al., 2013; Smedley, Stith, \& Nelson, 2003). Although these disparities have many sources, they result at least in part from patients' experiences in clinician-patient relationships. For example, in comparison to European American patients, African-American patients see themselves as being in worse health and receiving lower quality of care (Smedley et al., 2003). They are more likely to visit

\footnotetext{
*Corresponding author. Email: acuevas@hsph.harvard.edu
} 
the emergency department and they have fewer physician visits per year (Brown et al., 2012; Smedley et al., 2003). In the clinician's office, for example, physicians are more verbally dominant and engage in less patient-centred communication with AfricanAmerican patients than with White patients (Johnson, Roter, Powe, \& Cooper, 2004). Along with African-Americans, Latinas/Latinos report greater perceived discrimination compared to European Americans and these perceptions are associated with lower ratings of quality of care (Sorkin, Ngo-Metzger, \& De Alba, 2010). These perceptions may be amplified when Latinas/Latinos face language barriers. For example, limited English proficient (LEP) Latinas/Latinos with language-discordant physicians are more likely to have poor glycemic control than LEP Latinas/Latinos with language-concordant physicians (Fernandez et al., 2010). This finding suggests that language concordance is an important component to trust-building, medication comprehension, and overall receipt of quality of care for LEP Latinas/Latinos (Diamond \& Jacobs, 2010).

There is debate over the principal underlying sources of these disparities in clinician-patient relationships. Lower quality clinician-patient relationships for minority patients may arise from clinicians treating patients differently based on race/ethnicity. Clinicians may deliver higher quality, more patient-centred care to White patients due to cultural insensitivity, racial bias, or discriminatory treatment (Betancourt \& Green, 2010; Blair et al., 2013; Cooper et al., 2012; Penner et al., 2013). Alternatively, lower quality clinician-patient relationships for minority patients may arise from racial or ethnic differences between clinicians' and patients' preferences, beliefs, and values. Clinicians may deliver the same care to White and minority patients with the result that minority patients perceive lower quality care due to a lack of cultural tailoring (Betancourt \& Green, 2010; Saha, Beach, \& Cooper, 2008; Weech-Maldonado et al., 2012).

Cultural competency training has been adopted as health professionals' primary approach to addressing racial and ethnic disparities in health care, but currently such training varies widely. In the US some programmes focus on reducing provider bias and equalising the care provided to patients of varied ethnic groups, while other programmes focus on improving provider awareness and responsiveness to varying cultural norms and differentiating care for patients of colour vs. European American patients (Betancourt \& Green, 2010; Blair, Steiner, \& Havranek, 2011; Lie, Lee-Rey, Gomez, Bereknyei, \& Braddock, 2010; Penner et al., 2013). Patients' own voices, however, have been largely missing from the debate about how to improve clinician-patient relationships for minority patients and thus to reduce disparities in health care quality. In this study, we sought to understand the degree to which disparities in clinician-patient relationships arise from African-American and Latina/Latino patients being treated differently from European American patients when they would prefer to be treated the same vs. being treated the same when they would prefer to be treated differently. To accomplish this we used focus groups to explore the experiences and perspectives of African-American, Latina/Latino and European American patients on their clinicianpatient relationships.

\section{Method}

The study, known as Project EQUALED (Exploring the Quality of African American and Latina/Latino Experiences with Doctors), aimed to determine what constitutes good or bad relationships with clinicians from the perspectives of patients across three broad 
cultural groups comprised of African-Americans, Latinas/Latinos and European Americans. Employing several principles of community-based participatory research (CBPR; Israel, Schulz, Parker, \& Becker, 1998), our research team included two community liaisons as active research team members meeting weekly with academic project staff during the formative phases of the project. We also enlisted the guidance of a community advisory board which provided input into recruitment approaches as well as revisions of the focus group discussion guide. The advisory board also provided input into the design of study recruitment flyers. Word-of-mouth invitations from advisory board members and from initial research participants helped the research team to involve the participation of community members in the focus groups. Research team members conducted the focus groups in community settings including public libraries and a locally-owned coffee shop.

\section{Participant recruitment}

We wanted to hear the experiences and views of adult community residents who were diagnosed with diabetes and/or hypertension because people living with these illnesses are seen routinely in primary care. We posted study flyers in a variety of venues, including restaurants, stores, barber and beauty shops, and we enrolled people during community events in Portland (African-American participants) and Silverton, Oregon (Latina/Latino participants). To recruit for the European American groups we posted study flyers widely in predominately European American neighbourhoods of Portland, Oregon. We limited our efforts recruiting European American participants to neighbourhoods of modest socio-economic status in order that our comparisons across ethnicity would not be conflated with socio-economic differences. We avoided clinics and hospitals as recruitment sites because we wanted the sample to be truly community-based, not clinic-based, and because we did not want to oversample from any particular health care facility. We also asked participants and potential participants to talk about the study with other possibly eligible persons in their personal networks. The advertising flyers said that the project involved group discussion pertaining to the experiences that community members with diabetes, hypertension, or both of these, have with their doctors.

Upon telephoning the research office, interested community members were screened for eligibility (ethnicity and diabetes and/or hypertension diagnosis). Participants were told what some of the key questions would be in the focus group discussions (e.g. 'Tell us about a good experience you had with a doctor') and were briefed on key points that would be covered in the informed consent paperwork.

\section{Focus groups}

In keeping with principles of CBPR, moderators for the African-American and Latina/ Latino focus groups were recruited from these respective communities. Potential focus group moderators were first identified by community advisory board members and other community members. Potential moderators underwent an initial eight-hour training session addressing principles of focus group research, and including moderator practice as well as human subjects training. Moderators also received coaching throughout the study period. Each moderator also received an individual copy of the volume Moderating Focus Groups (Krueger, 1997). Focus groups with European American participants 
were moderated by European American members of the research team with assistance from another European American moderator.

Focus groups were segmented by ethnicity and gender, with moderators matched to discussion participants on these key characteristics. Typically one co-moderator asked questions and led discussion while the other co-moderator took notes and monitored the discussion to ensure balanced participation. The interviews were semi-structured in order to allow moderators the freedom to probe interesting topics that arose during the sessions (Tong, Sainsbury, \& Craig, 2007). All focus groups with Latina/Latino community members were conducted in Spanish. Simultaneous translation using a remote microphone was used in order to allow research team members to follow the focus group discussions in real time (Esposito, 2001).

Focus groups began 15 to $20 \mathrm{~min}$ or so after the first participants arrived so that almost all participants had time to meet the members of the research team. Each place setting at the discussion table included informed consent paperwork that participants were able to review at their own pace before the discussion began; team members also answered individual participants' questions about the study.

The focus group guide employed by the moderators was intended to solicit participants' actual experiences in the health care system with particular attention to their interactions with physicians, including participants' values and preferences relating to these interactions. The guide included questions about participants' most recent visit to the doctor, their good experiences with doctors (and what makes a good experience), their bad experiences with doctors (and what would have made for a better experience), their experiences and preferences if any regarding a physician's race/ethnicity, their perspectives on important relationship dimensions such as trust and respect, and their advice to doctors for improving the way doctors work with patients. Focus group participants were compensated $\$ 40$ for their time. Study procedures were approved by the Oregon Health \& Science University Institutional Review Board.

\section{Analysis}

The focus group discussions were audiorecorded. All dialogue was transcribed and transcriptions were placed into Microsoft Word documents. Documents were then imported into the qualitative software, NVivo 10, and each focus group was given its own file. The academic research team employed a thematic analysis approach in the analysis of transcripts, including six phases: familiarising with data, generating initial codes, searching for themes among codes, reviewing themes, defining and naming themes, and producing the final report (Braun, Clarke, \& Terry, 2014). Because the goal of the project was to report patients' experiences and preferences regarding the patient-clinician relationship in patients' own terms, the team adopted a realist framework for data analysis (Braun \& Clarke, 2006).

In the first phase of analysis, three team members read the transcripts to become familiar with the content and discuss potential patterns that might exist in the data. In the second phase two team members independently coded $25 \%$ of the transcripts. Coders also kept notes (or memos) on issues on which they anticipated a need for clarification. All three team members then met to compare codes, to discuss areas of divergence and to reach agreement on coding and organisation. In these discussions, team members took care to keep codes close to the transcript content, not yet identifying 
themes. After code agreement was reached, one team member (the first author) coded the remainder of the transcripts, applying a common set of codes and sub-categories across all transcripts. During the third and fourth phases, the team members met frequently to discuss codes, particularly any newly emerging codes, and to reach agreement on the codes and sub-categories. They then reviewed the codes to develop themes capturing the essence of the given data. The team then discussed relationships between subthemes and the overarching themes. The team then examined patterns of difference and similarity across the three participant ethnic groups. During this process, the three team members were mindful of the different perspectives they brought to this analysis due to their backgrounds, with one investigator being a scholar of Latina/Latino and African-American descent, two being social scientists, and one being a practicing primary care physician. Throughout the process, the research team reviewed analytic memos, discussed discrepancies of thinking, and reached agreement on analytic findings.

\section{Results}

A total of 142 adults participated in 27 focus groups segmented by ethnicity and gender, including five groups of African-American women, five groups of African-American men, five groups of Latina women, four groups of Latino men, four groups of European American women and four groups of European American men.

Appendix 1 presents our summary of thematic findings, including both commonalities and differences among the three ethnic groups. In general we found substantially more commonalities than differences in patients' preferences for care and in how they described good and bad experiences. Patients of all groups described experiences that reflected the concepts of patient-centred care. Across the three groups, patients wanted a personable provider who listened to their comments and paid attention to their problems. Patients also expressed their desire to be more participatory in the interactions with their providers and be more involved in their own care. Supplementary to these preferences, they wanted their clinicians to be attentive and sensitive to their needs. The following quote from one of the African-American men participating in the study illustrates the common themes of open communication, listening, and valuing a patient's perspective on the treatment regimen that were expressed by members in all three ethnic groups.

[What I would like from a doctor is] open communication. Being able to give and receive information. Being attentive to the patient's needs. Taking recommendations from the patient, you know, vs. always just on the tell and tell and tell, because the bottom line, you know your body better than anybody else. Now, the doctor's there to help you understand what's going on, but like the gentleman was saying down here, when he was in Alabama, all he knew, his foot was hurting. And then he came and told the doctor what was going on. He had to give him the information. And the doctor had to be able to listen to that, and then when he listened to that, then he was able to do what he was supposed to do. So it has to be open communication on both ends.

\section{Ethnic difference in preferences}

While the three groups shared similar criteria for good patient-provider relationships, there were some differences in preferences across ethnic groups. 


\section{Acknowledging patients' racial/ethnic background}

Some African-American patients felt it was important for clinicians to consider the patient's race in providing health care. For example, this patient felt clinicians should consider his racial/ethnic identity in working with him and formulating a treatment plan:

I expect him just to be polite and nice to me, and not just treat me as just another patient, another piece of my income, you know, you're just another patient, another income. Treat me like, yes, this is a Black man, this is a Black man with diabetes, this is a Black man with diabetes and high blood pressure. I know that we have a problem with this as a race. I've learned other things being a Black man, about this particular problem that we have, and I'm going to inform him a little better than other people or, if I'm not going to inform him better than other people, I'm going to get him somebody that can.

\section{Preference for ethnic and language concordance}

African-Americans varied in their preferences regarding the race of their physicians. Many African-Americans said they did not care whether their doctor was African-American or not as long as the doctor was competent. Similarly, European American patients reported indifference about physicians' race. They wanted a clinician who showed respect and attentiveness during the interaction. Unlike the European Americans and many of the African-Americans, most Latinas/Latinos preferred an ethnic- or languageconcordant provider. Some did not have a preference for an ethnic-concordant provider as long as the provider knew Spanish, while others preferred a Latina/Latino provider, believing that Latina/Latino providers understand Latina/Latino experiences. The patients believed that language-concordant providers and ethnic-concordant providers communicate effectively with patients, enabling patients to understand their providers' recommendations and allowing physicians to understand their patients' explanations of their symptoms. For example, this Latino male participant preferred

Latina/Latino clinicians because he felt patient and clinician would understand each other better:

I think the, the majority of us try to look for Latino doctors, because first of all the communication that I think more than anything that's really indispensable. Just understanding each other. And by understanding each other, the results of the doctor will be better, because they know exactly the problem we have. At least I, where I go, they're all Hispanic. And I feel good, I feel good going there.

Some Latinas/Latinos preferred that clinicians be knowledgeable about complementary and alternative medicine and spoke about their own use of alternative medicine to complement medicines obtained by prescription. Because they were concerned that the alternative medicine might cause complications, Latinas/Latinos wanted providers to be informed and to have better connections with herbalists. As this Latina participant said:

I would like my doctor to speak Spanish, but I would like them to know more about alternative medicine, like herbs, cause I use that a lot. I use a lot of Chinese medicine and herbs. I would like them to ask me about going to a curandero ... 
There's a lot of people nowadays that use that kind of medicine and therapy. I would like for them to ask me that question ... [I want them] to study more about alternative medicine, so they can have an intelligent conversation with the patients and know that that doesn't coincide with the medicine he wants to give me. Not just say, 'No, don't take it.'

\section{Ethnic difference in experience}

\section{Perceived discrimination among African-Americans}

Some African-American participants had experienced negative events before they saw the clinician, including long waits in the waiting or exam room. While some patients did not know whether the long waits were based on their ethnic background or not; these ambiguous events negatively influenced their health care experience prior to seeing the clinician. African-American patients also spoke about the personable welcomes they sometimes observed European American patients receiving from non-medical staff compared to the cold, business-like greetings they themselves received and indicated that this negatively affected their mood. One woman shared her experience about the unequal treatment she received from non-medical staff.

Well, um, my primary care doctor, doctor of internal medicine, is very helpful towards me, and she goes out of her way to help me, but I notice ... when I'm in the receptionists' area, the receptionists seem more willing to chit-chat with the white clients that come through than they are with me. They'll have them standing there talking to them and laughing and joking, and when I step up and make a comment, you know, it's all business. I feel (laughs), I feel like they're prejudiced.

In the clinician's office, African-Americans often perceived unfair treatment from their clinicians. Many African-Americans felt that clinicians did not provide them with pain medication because clinicians perceived them as drug users. For example, this AfricanAmerican woman shared her experience dealing with pain and how she felt she did not receive medication because clinicians see African-Americans as drug addicts.

When I flare all up, I take something, you know, so I like to have something just because my pain goes from my toes all the way up to my neck and shoulders sometimes. I can hardly function, and I need something, and that's why I've been saying, give me something or tell me something I can do. I need help and that's my biggest gripe. I think it's because I'm a Black woman I don't get no medication or no kind of other kind of treatment because we got a reputation of being drug addicts and stuff.

\section{Discrimination based on health insurance coverage}

African-Americans perceived discrimination within the health care system based on the insurance they had or lacked. They felt they would receive better treatment if they had better insurance coverage. For example, this patient mentioned that he felt that the health care staff treats patients better if they have insurance. He believed that hospitals are businesses that give preferential treatment to those with insurance.

And this is a good example of how when, you know, even though, in the medical, in the medical field, it still, the overarching ... the denominator is dollars and cents. If you have insurance, they will treat you ... they will roll out the red carpet. If you don't, I mean, it's challenging. And so [they] rush me out the hospital ... Unfortunately, the hospital is a 
business, I mean, it's a business, and at the end of the day, they sitting down seeing ... Well, that's our life.

Similar to African-Americans, European Americans felt their lack or availability of insurance played a role in the health care service they received. For example, this patient described her experience of being refused service because of her lack of health care insurance.

I lived in another city and I had some very serious heart problems, so they sent me to Portland and I was admitted to this hospital and they started running all these tests ... I went in to the doctor to make the arrangements and he said, 'I'm going to have to send you home.' My husband says 'You're going to send her home, why?' And this doctor says, 'Because you have no insurance.' And my husband says 'Are you sending her home to die?' and he says 'Yes, basically that's what I'm doing,' and I got up and walked out the door. They called me back, they told my husband that 3 more minutes and I would have been dead. And I had a 2-way bypass, but I was refused at one of the hospitals in Portland because of no insurance.

\section{Discussion}

We explored the degree to which disparities in the quality of clinician-patient relationships arise from ethnic minority patients being treated differently than European American patients when those minority patients would prefer to be treated the same as European American patients, vs. the ethnic minority patients being treated the same as European American patients when preferring to be treated differently. Although we found evidence for both, our findings suggest that in general, patients have similar preferences but receive unequal treatment. There were substantially more commonalities than differences in patients' preferences for care and in how they described good and bad experiences. Patients of all groups described preferences reflecting the concepts of patient-centred care (Epstein \& Street, 2011), in that patients wanted a personable provider who listened to their comments and was attentive and sensitive to their needs. Patients also expressed their desire to be more involved in their own care.

While preferences for care were mostly similar across groups, experiences differed in ways that patients, particularly African-American patients, perceived as discriminatory. Long waits in the waiting room or exam room made many wonder whether the delay was a response to their racial or ethnic background, negatively influencing their health care experience prior to seeing the clinician. During the wait, many felt that the non-medical staff treated them differently than European American patients. They perceived the interaction between office staff and European American patients as warm and welcoming, and their own interaction with office staff as cold and business-like. African-Americans also often perceived unfair treatment from the clinicians themselves. Many African-Americans felt that clinicians did not provide them with pain medication because clinicians perceived them as drug users.

There were some differences in preferences within and across ethnic groups. Some African-American patients felt clinicians should take patients' race/ethnicity into account when discussing their health. They felt that clinicians may be able to deliver better care if the patients' race were acknowledged. Some Latinas/Latinos preferred ethnic- or language-concordant providers. They believed that these providers were more 
proficient communicators who helped them understand the treatment regimen and allowed them to share their perspectives about their own health. Lastly, some Latinas/ Latinos who used alternative medicines (e.g. herbs and roots) wanted providers to be more knowledgeable of alternative medicine and discuss how it may or may not complement their current treatment regimen. It is not surprising that Latina/Latino patients preferred ethnic- or language-concordant providers. The extant literature shows that Latinas/Latinos report health care problems pertaining to cultural issues, language, and lack of culturally-matched health care providers (González, Vega, \& Tarraf, 2010; Timmins, 2002). However, we were surprised that many African-American patients were indifferent on the question of race-concordant physicians. Upon further reflection we believe that African-American patients may not view the clinician's race as important as other dimensions of the clinician's characteristics, such as communication style (Dale, Polivka, Chaudry, \& Simmonds, 2010). Sacks (2013) also did not find a uniform preference for race concordant providers among African-American female patients. She found that the environmental constraints in health care (e.g. wait times, quality of interpersonal interactions) were more important for the patients than having a race concordant clinician. Based on our findings as well, most African-Americans did not believe that having race concordant clinicians would in itself assure the delivery of quality health care. In contrast, Latinas/Latinos in our study felt that having culturally-matched providers would assure good quality of care. Because this was a salient issue for them, the need felt by Latinas/Latinos for an ethnically concordant clinician may have kept Latinas/Latinos from mentioning other barriers that also affect their health care experiences. In sum, our findings indicate that racial or ethnic concordance is not always identified by patients themselves as important; even so, improving access to culturallysensitive health care may help address many concerns of minority patients.

Using focus groups, Tucker et al. (2003) found that African-American, Latina/ Latino and European American primary care patients shared similar values, reflecting dimensions of patient-centred care. For example, patients preferred providers that had 'people skills' such as listening and expressing empathy. They also preferred individualised treatment in which the provider made them feel special. Tucker and colleagues also revealed some ethnic-group-specific themes. For example, African-Americans expressed dissatisfaction with the lack of culturally-tailored materials for AfricanAmericans in patient waiting areas, and with the insensitive behaviours exhibited by the medical staff. Latinas/Latinos expressed concerns about the impact of language barriers on their levels of trust and comfort with their clinicians. Barr and Wanat (2005) found similar results. In their focus group study, African-Americans expressed concerns about the lack of culturally appropriate informational materials at health care organisations and the rude, unhelpful medical staff. Latinas/Latinos reported the unavailability of Spanish-speaking staff, incompetent interpreters, and physicians' intolerance towards patients with limited English proficiency. Interestingly, discrimination was a pervasive theme among Latinas/Latinos in both the Tucker et al. (2003) and Barr and Wanat (2005) studies, but was not a major theme among Latinas/Latinos in our study. This difference may have been driven by the focus group questions, by moderators' facilitation of discussions or by regional differences in care.

The reports from African-American and Latina/Latino participants in our study may echo reports by members of other ethnic minority groups in the US or other geographic settings. In Aotearoa/New Zealand, for example, work by Cram, Smith, and Johnstone 
(2003) found that when asked to describe health care experiences in a focus group context, many Māori patients reported past discriminatory experiences in health care either for themselves or for important others in their lives. Māori patients reported a cultural disconnect between themselves and non-Māori clinicians. Similar to participants from all three ethnic groups in our own study, Māori patients expressed the importance of interpersonal rapport with clinicians including clinicians listening to them and attending to their needs. Conversely, research by McCreanor and Nairn (2002) into the ways that physicians talked about Māori patients' needs revealed patterns of physician language that often construed protocol non-adherence as a problem arising from patients' health attitudes or from Māori culture - rather than patterns of language that sought to understand how patients viewed their own needs.

While our findings provide a better understanding of patients' perspectives and experiences with health care, there are some limitations to this study that need to be considered. We recruited community members from only three ethnic groups. We focused on African-Americans, Latinas/Latinos and European Americans as they are the three largest racial or ethnic groups in the United States (USA QuickFacts from the US Census Bureau, 2014). Community members were recruited from Oregon, a state in the US with a predominantly White population (USA QuickFacts from the US Census Bureau, 2014); African-Americans' and Latinas/Latinos' experiences of being minority group members may differ from residents of other regions. For example, AfricanAmericans in Portland or Latinas/Latinos in Silverton may have few opportunities to see a non-White clinician, which may limit their sharing of narratives about raceconcordant clinicians. Further, Latina/Latino focus group members were Spanish-speaking immigrants all or almost all of Mexican descent, whose health care experiences may differ from non-immigrant Latinas/Latinos or from other Latina/Latino immigrants. In addition, we investigated patients' reports about their experiences in health care, but we did not directly observe these experiences. While direct observation may provide a better understanding of actual patient experiences, patients' reports provide the best evidence of how experiences are internalised. Lastly, we employed a realist framework to our analyses, which limits the research team from engaging the findings within the sociocultural and structural contexts of the patients. Although a constructionist framework would have allowed us to address structural and societal conditions that affect patients' health care experiences, the purpose of Project EQUALED was to give voice to patients' own health care experiences and perspectives concerning patient-clinician relationships. Rather than asking patients to contextualise their experiences, we intentionally focused on the factors considered by patients themselves to facilitate or impede quality health care.

Despite these limitations, this study offers insight into opportunities for cultural competency training to improve quality of care for ethnic minority patients. In the study, patients across groups expressed strong sentiments about receiving patient-centred care, suggesting the importance of a patient-centred approach to cultural competency training (Epner \& Baile, 2012; Tucker, Marsiske, Rice, Nielson, \& Herman, 2011). Using a patient-centred care approach may help clinicians identify and negotiate different styles of communication, decision-making preferences, family roles, sexual and gender issues, and issues of mistrust and racism (Epner \& Baile, 2012).

Evidence in the literature that clinicians' explicit and implicit biases negatively affect patient-provider interactions (Penner et al., 2013) coupled with the finding in the 
current study that African-American patients perceived discrimination and bias from clinicians and medical staff indicates that targeting clinical and non-clinical staff attitudes and behaviours is an important aspect of training to reduce disparities in health care delivery (Cuevas, O’Brien, \& Saha, 2016). Emphasising aspects such as cultural sensitivity and awareness may help reduce both conscious and unconscious biases towards members of ethnic minority groups.

Some African-Americans and Latinas/Latinos preferred care that was culturally tailored. For example, some African-American patients felt it was appropriate to contextualise their care racially and ethnically, while most Latinas/Latinos preferred languageand culturally-concordant clinicians. It is important, however, to proceed with caution in acting on these findings, because they can potentially lead to stereotypical teaching strategies (such as treating all African-Americans in a particular manner), which may have adverse effects on patients' experiences. It is also unrealistic for health care providers to become experts in working with members of all cultural and ethnic groups; it may be reasonable, however, for providers to understand the cultural contexts of the major ethnic groups in their patient population. Providers can collaborate with language interpreters or with cultural brokers, who serve as mediators between the culture of the patient's group and both the majority culture and the culture of medical institutions, in order to improve patients' experiences (Brisset, Leanza, \& Laforest, 2013; Nápoles, Santoyo-Olsson, Karliner, Gregorich, \& Pérez-Stable, 2015). Increasing the number of African-American and Latina/Latino clinicians would afford more opportunities for race concordance with African-American and Latina/Latino patients in order to provide improved quality of care. Yet, we have to proceed with caution with this suggestion. Based on our findings, increasing the number of minority staff and physician alone may not resolve the many issues that these patients feel are barriers to receiving appropriate care.

Important though it is, the patient-clinician relationship is not the only pathway to reducing health care disparities for African-Americans and Latinas/Latinos. Societal structures such as employment, access to quality care and segregation likely give rise to many of these disparities and cannot be ignored (White, Haas, \& Williams, 2012; Williams, Mohammed, Leavell, \& Collins, 2010; Zuvekas \& Taliaferro, 2003). To comprehensively address health care disparities, efforts to improve patient-clinician relationships will need to be combined with other initiatives aimed at reducing institutionally discriminatory practices and addressing other barriers, including inadequate access to care, limited English proficiency and low health literacy (Shavers \& Shavers, 2006).

\section{Conclusion}

In this study, we explored whether disparities in patient-clinician relationships arise from ethnic minority patients being treated differently from European American patients, when they would prefer similar treatment vs. ethnic minority patients preferring to be treated differently than European American patients. We found evidence for both viewpoints, suggesting that a patient-centred approach to cultural competency training, responsive to individual patient concerns and coupled with general knowledge of the cultural context of the major population groups being cared for, may reduce disparities in the quality of care patients receive. Increasing workforce diversity and 
collaborating with interpreters and cultural brokers may help facilitate these efforts. Attention to the negative effects of racial bias and discrimination among clinicians and non-clinical staff could also lead to greater equity in health care delivery.

\section{Acknowledgements}

We thank study participants as well as the community leaders and organisations whose expertise and collaboration helped to create Project EQUALED and ensure its success.

\section{Disclosure statement}

No potential conflict of interest was reported by the authors.

\section{Funding}

Project EQUALED was funded by a grant from the Robert Wood Johnson Foundation. The preparation of this article was supported by the National Institute of Health 3R25CA057711. Its contents are solely the responsibility of the authors and do not necessarily represent the official views of the NIH.

\section{References}

Barr, D. A., \& Wanat, S. F. (2005). Listening to patients: Cultural and linguistic barriers to health care access. Family Medicine, 37, 199-204.

Betancourt, J. R., \& Green, A. R. (2010). Commentary: Linking cultural competency training to improved health outcomes: Perspectives from the field. Academic Medicine, 65, 583-586.

Blair, I. V., Steiner, J. F., Fairclough, D. L., Hanratty, R., Price, D. W., Hirsh, H. K., ... Havranek, E. P. (2013). Clinicians' implicit ethnic/racial bias and perceptions of care among Black and Latino patients. The Annals of Family Medicine, 11, 43-52.

Blair, I. V., Steiner, J. F., \& Havranek, E. P. (2011). Unconscious (implicit) bias and health disparities: Where do we go from here. The Permanente Journal, 15, 71-78.

Braun, V., \& Clarke, V. (2006). Using thematic analysis in psychology. Qualitative Research in Psychology, 3, 77-101.

Braun, V., Clarke, V., \& Terry, G. (2014). Thematic analysis. In P. Rohleder \& A. Lyons (Eds.), Qualitative Research in Clinical and Health Psychology (pp. 95-113).

Brisset, C., Leanza, Y., \& Laforest, K. (2013). Working with interpreters in health care: A systematic review and meta-ethnography of qualitative studies. Patient Education and Counseling, 91, 131-140.

Brown, L. E., Burton, R., Hixon, B., Kakade, M., Bhagalia, P., Vick, C., ... Hawn, M. T. (2012). Factors influencing emergency department preference for access to healthcare. Western Journal of Emergency Medicine, 13, 410-415.

Cooper, L. A., Roter, D. L., Carson, K. A., Beach, M. C., Sabin, J. A., Greenwald, A. G., \& Inui, T. S. (2012). The associations of clinicians' implicit attitudes about race with medical visit communication and patient ratings of interpersonal care. American Journal of Public Health, 102, 979-987.

Cram, F., Smith, L., \& Johnstone, W. (2003). Mapping the themes of Māori talk about health. New Zealand Medical Journal, 116(1170), 1-7.

Cuevas, A. G., O'Brien, K., \& Saha, S. (2016). African American experiences in healthcare: "I always feel like I'm getting skipped over". Health Psychology, 35, 987-995. 
Dale, H. E., Polivka, B. J., Chaudry, R. V., \& Simmonds, G. C. (2010). What young African American women want in a health care provider. Qualitative Health Research, 20, 1484-1490.

Diamond, L. C., \& Jacobs, E. A. (2010). Let's not contribute to disparities: The best methods for teaching clinicians how to overcome language barriers to health care. Journal of General Internal Medicine, 25, 189-193.

Epner, D. E., \& Baile, W. F. (2012). Patient-centered care: The key to cultural competence. Annals of Oncology, 23, 33-42.

Epstein, R. M., \& Street, R. L. (2011). The values and value of patient-centered care. The Annals of Family Medicine, 9, 100-103.

Esposito, N. (2001). From meaning to meaning: The influence of translation techniques on non-English focus group research. Qualitative Health Research, 11, 568-579.

Fernandez, A., Schillinger, D., Warton, E. M., Adler, N., Moffet, H. H., Schenker, Y., ... Karter, A. J. (2010). Language barriers, physician-patient language concordance, and glycemic control among insured Latinos with diabetes: The Diabetes Study of Northern California (DISTANCE). Journal of General Internal Medicine, 26, 170-176.

González, H. M., Vega, W. A., \& Tarraf, W. (2010). Health care quality perceptions among foreign-born Latinos and the importance of speaking the same language. The Journal of the American Board of Family Medicine, 23, 745-752.

Israel, B. A., Schulz, A. J., Parker, E. A., \& Becker, A. B. (1998). Review of community-based research: Assessing partnership approaches to improve public health. Annual Review of Public Health, 19, 173-202.

Johnson, R. L., Roter, D., Powe, N. R., \& Cooper, L. A. (2004). Patient race/ethnicity and quality of patient-physician communication during medical visits. American Journal of Public Health, 94, 2084-2090.

Krueger, R. A. (1997). Moderating focus groups (Vol. 4). Thousand Oaks, CA: Sage.

Lie, D. A., Lee-Rey, E., Gomez, A., Bereknyei, S., \& Braddock, C. H. (2010). Does cultural competency training of health professionals improve patient outcomes? A systematic review and proposed algorithm for future research. Journal of General Internal Medicine, 26, 317-325.

McCreanor, T., \& Nairn, R. (2002). Tauiwi general practitioners' talk about Maori health: Interpretive repertoires. The New Zealand Medical Journal, 115(1167), 1-8.

Nápoles, A. M., Santoyo-Olsson, J., Karliner, L. S., Gregorich, S. E., \& Pérez-Stable, E. J. (2015). Inaccurate language interpretation and its clinical significance in the medical encounters of Spanish-speaking Latinos. Medical Care, 53, 940-947.

National Center for Health Statistics. (2016). Health, United States, 2015: With special feature on racial and ethnic health disparities. Hyattsville, MD: National Center for Health Statistics (US). Retrieved from http://www.ncbi.nlm.nih.gov/books/NBK367640/

Penner, L. A., Hagiwara, N., Eggly, S., Gaertner, S. L., Albrecht, T. L., \& Dovidio, J. F. (2013). Racial healthcare disparities: A social psychological analysis. European Review of Social Psychology, 24, 70-122.

Sacks, T. K. (2013). Race and gender concordance: Strategy to reduce healthcare disparities or red herring? Evidence from a qualitative study. Race and Social Problems, 5, 88-99.

Saha, S., Beach, M. C., \& Cooper, L. A. (2008). Patient centeredness, cultural competence and healthcare quality. Journal of the National Medical Association, 100, 1275-1285.

Shavers, V. L., \& Shavers, B. S. (2006). Racism and health inequity among Americans. Journal of the National Medical Association, 98, 386-396.

Shi, L., Lebrun-Harris, L. A., Daly, C. A., Sharma, R., Sripipatana, A., Hayashi, A. S., \& Ngo-Metzger, Q. (2013). Reducing disparities in access to primary care and patient satisfaction with care: The role of health centers. Journal of Health Care for the Poor and Underserved, 24, 56-66.

Smedley, B. D., Stith, A. Y., \& Nelson, A. R. (2003). Unequal treatment: Confronting racial and ethnic disparities in health care (full printed version). Washington, DC: National Academies Press. 
Sorkin, D. H., Ngo-Metzger, Q., \& De Alba, I. D. (2010). Racial/ethnic discrimination in health care: Impact on perceived quality of care. Journal of General Internal Medicine, 25, 390-396.

Timmins, C. L. (2002). The impact of language barriers on the health care of Latinos in the United States: A review of the literature and guidelines for practice. Journal of Midwifery \& Women's Health, 47, 80-96.

Tong, A., Sainsbury, P., \& Craig, J. (2007). Consolidated criteria for reporting qualitative research (COREQ): A 32-item checklist for interviews and focus groups. International Journal for Quality in Health Care, 19, 349-357.

Tucker, C. M., Herman, K. C., Pedersen, T. R., Higley, B., Montrichard, M., \& Ivery, P. (2003). Cultural sensitivity in physician-patient relationships perspectives of an ethnically diverse sample of low-income primary care patients. Medical Care, 41, 859-870.

Tucker, C. M., Marsiske, M., Rice, K. G., Nielson, J. J., \& Herman, K. (2011). Patient-centered culturally sensitive health care: Model testing and refinement. Health Psychology, 30, 342-350.

USA QuickFacts from the US Census Bureau. (2014). Retrieved November 5, 2015, from http://quickfacts.census.gov/qfd/states/00000.html

Weech-Maldonado, R., Elliott, M. N., Pradhan, R., Schiller, C., Hall, A., \& Hays, R. D. (2012). Can hospital cultural competency reduce disparities in patient experiences with care? Medical Care, 50, S48-S55.

White, K., Haas, J. S., \& Williams, D. R. (2012). Elucidating the role of place in health care disparities: The example of racial/ethnic residential segregation. Health Services Research, 47, $1278-1299$.

Williams, D. R., Mohammed, S. A., Leavell, J., \& Collins, C. (2010). Race, socioeconomic status and health: Complexities, ongoing challenges and research opportunities. Annals of the New York Academy of Sciences, 1186, 69-101.

Zuvekas, S. H., \& Taliaferro, G. S. (2003). Pathways to access: health insurance, the health care delivery system, and racial/ethnic disparities, 1996-1999. Health Affairs, 22, 139-153. 
Appendix 1. Differences and commonalities among focus group reports from three ethnic groups

Commonalities in preferences $\quad$ Differences in preferences $\quad$ Differences in experiences

- Patients wanted a doctor who listens

- Patients wanted a doctor who is attentive to patients' needs

- Patients wanted a doctor who is sensitive to patients' needs

- Patients wanted to be more participatory in interactions with their doctors and more involved in their own care
- African-Americans preferred clinicians who acknowledged their racial/ ethnic background

- Latinas/Latinos reported a desire for ethnic and language concordance

- Latinas/Latinos preferred expertise regarding complementary and alternative medicine

- European Americans expected that female doctors, more than male doctors, show care and compassion
- African-Americans perceived discrimination in the doctor's office

- African-Americans perceived discrimination in the waiting room

- African-Americans and European Americans perceived discrimination based on health insurance coverage 